\title{
Televidencias y lecturas de puesteros sobre el discurso presidencial de Rafael Correa
}

\section{Television views and readings from stall holders about Rafael Correa's presidential speech}

Recibido: 26/07/2019

Aceptado: 04/10/2019

Publicado: 05/12/2019

\author{
Byron Andino Veloz \\ bayron.andino@perio.unlp.edu.ar \\ Universidad Nacional de La Plata (Argentina)
}

Resumen: El artículo muestra los resultados de un estudio de recepción en los puesteros de la Feria libre de La Ofelia (Quito, Ecuador), sobre el discurso presidencial de Rafael Correa (1/V/2015). Los objetivos fueron analizar sus mediaciones, televidencias y qué lecturas dominantes, negociadas u oposicionales tienen los vivanderos acerca del discurso presidencial. Esto se incluye en el proceso de construcción de identidades políticas en relación con la conformación discursiva del "pueblo", con su inicial construcción, así como sus límites, debilidades y declive. La investigación refleja las mediaciones sociales de los comerciantes de esa feria como grupo subalterno y comunidad interpretativa. Se utilizó la técnica de entrevistas y visionados con un video de discursos de Correa para obtener las lecturas sobre el discurso presidencial.

Palabras clave: Política, Ecuador, Populismo, Estudios de recepción, Sentidos.

Abstract: This paper presents the reception study's results on the senses produced in vendors, which are located in La Ofelia Public Market (Quito, Ecuador) over the presidential speech of the Ecuadorian president, Rafael Correa 
(1/V/2015). This investigation analyzed the dominant/hegemonic, negotiated and oppositional positions of vendors over the presidential speech. In addition, it investigated how the sense was produced in vendors as an interpretative community. This process is involved in building political identities. This text also reflects the social mediations on vendors of that fair, as a subaltern group, which is an interpretive community. With interviews and a viewing of Correa speech was obtained the readings on the presidential speech.

Key words: Politics, Ecuador, Populism, Reception studies, Senses.

\section{Introducción}

Este texto se desarrolló a partir de una investigación ${ }^{1}$, cuyo objetivo general era explorar la construcción social de sentido sobre el discurso presidencial de Rafael Correa y su evocación al pueblo (a través de un estudio de recepción) cuando habían transcurrido casi diez años de gobierno. Estaba a poco de culminar su gestión y se presentaba cierto declive en el respaldo hacia su proyecto político (en relación con la hegemonía que poseía).

Para entender el contexto previo a ese proceso político, Ecuador vivió un periodo de fragilidad con varios derrocamientos de mandatarios desde 1996 y una crisis económica que tuvo su punto más crítico en 1999. Fue un periodo de gobiernos débiles: hubo siete presidentes en nueve años antes de la llegada de Rafael Correa al mandato. Desde el 2007, Correa brindó estabilidad y gobernabilidad. Sin embargo, la importancia que le dio a las estrategias de comunicación, aparte de difundir sus acciones gubernamentales, fuera para atacar a opositores, a las élites y medios de comunicación privados y hegemónicos, lo que motivó sentidos críticos sobre ellos. Asimismo, evocó la construcción discursiva del pueblo con el líder como elemento relevante (De la Torre, 2012).

El interés del trabajo radicaba en aplicar las teorías de las mediaciones múltiples, las televidencias y los tipos de lecturas para visibilizar el proceso de

1. El presente artículo está basado en la tesis de maestría del autor, titulada "Sentidos producidos entre los comerciantes del mercado La Ofelia, en Quito, sobre el discurso populista del presidente Rafael Correa" (Andino Veloz, 2017), defendida en la Universidad Andina Simón Bolívar (Ecuador). 
comunicación y significación en el tema político. De ahí que los objetivos específicos indagaron acerca de las multimediaciones de los sujetos de estudio para la generación de significados, así como el análisis de las televidencias (Orozco, 2014). El consumo de la televisión es hegemónico, por parte de la población de estudio del presente trabajo, que se constituyen como lecturas dominantes, negociadas u oposicionales (Hall, 2004), con relación al discurso de Rafael Correa.

Los sujetos de estudio son comerciantes populares (también llamados "puesteros", "vivanderos" o "tenderos") de la feria libre de La Ofelia, ubicada en el norte de Quito, capital de Ecuador. Estos conforman una población multiétnica, con mayor presencia de mujeres y de condiciones socioeconómicas media y baja. Estos grupos fueron parte del discurso de Correa como destinatarios. Además, la feria es un sitio de mediación con interacciones cara a cara, que permiten la negociación de sentidos posterior al consumo mediático y de discursos políticos. La información para este estudio se obtuvo entre el segundo semestre de 2016 y a inicios de 2017, pues Correa dejó el mandato en mayo de 2017.

Este artículo pretende ser un aporte para los estudios de recepción del discurso político en el que se conozcan los sentidos de la ciudadanía y se indague qué relación tienen con la construcción discursiva del pueblo y de las identidades políticas que impulsaba Correa. Hay que recalcar la existencia de propuestas analíticas con objetos de estudio similares en Ecuador (Cerbino, Maluf y Ramos, 2016; Onofa, 2012), que también acuden a los estudios de recepción sobre el discurso de Rafael Correa, pero desarrollados en otros contextos temporales y con sujetos de estudio distintos.

El presente contenido incluye un marco teórico sobre el sujeto político 'pueblo’ y el discurso de Rafael Correa, así como de los estudios de recepción; la propuesta teórico-metodológica con el análisis de las multimediaciones; así como los resultados y análisis de las televidencias y lecturas de los puesteros de la feria libre de La Ofelia.

\section{La construcción del "pueblo" y formación de identidades políticas}

El sujeto de lo político se refiere al principal agente que desarrolla la capacidad de ruptura o transformación en un orden hegemónico. Por ejemplo, 
Laclau (2005) y Dussel (2006) consideran que el sujeto de cambio social es el pueblo, el cual permite la conformación de identidades colectivas con pluralidad para representar a un todo subalterno.

Laclau (2005) concibe el populismo como una lógica de construcción política con un sistema de reglas que establecen objetos representables (movimientos de la cadena equivalencial) y otros excluidos (el resto, la oligarquía, las élites), que muestran el antagonismo necesario para luchar por sus demandas populares y sociales insatisfechas mediante la articulación de la diferenciación. Esto es alcanzar una cadena equivalencial con pluralidad de demandas heterogéneas de grupos sociales mediante el pueblo.

Estas agrupaciones también se aglutinan por el significante vacío, que es la representación del pueblo en una persona. A esta visión se refiere Delsol (2016), al indicar que el populismo incursiona para reforzar la democracia con el pueblo y que si no funciona la democracia representativa, el líder sería la nueva representación en conexión con el pueblo. Esto lo logra mediante su acción discursiva y política, con el objetivo de alcanzar esa articulación de grupos heterogéneos.

Laclau (2005, pp. 199 y ss.) manifiesta que el proceso de representación entre el pueblo y el significante vacío debería ser dialógico; sin embargo, debe prevalecer la representación desde representados hacia el representante. Si el discurso de Rafael Correa apunta a la construcción del pueblo, entonces acude a la formación de identidad para articularla al proceso político. El peligro es construir identidades que tengan prácticas sociales contrarias a las necesidades del tejido social, es decir, que por creer y reproducir ciertas ideas de un líder, al final sea afectado el mismo pueblo, su capacidad de discusión y participación (Hawkins, 2008, p. 130).

Laclau (2005) y Martín-Barbero (1987) rechazan que los sujetos sean pasivos, irracionales y peligrosos al conformar el pueblo. Ambos mencionan en sus obras a Freud para criticar la deslegitimación académica sobre la exaltación de los sentimientos, para cuestionar la noción de "sugestión" que es contagio o manipulación pura del pueblo. Así, las identidades políticas están en disputa y los sujetos son ajenos a un estado hipnótico y débil (Sfez, 2007, p. 54). Con estos postulados, se considera a los sujetos de estudio (los puesteros) como sujetos históricos en el proceso hegemónico. 
Para ese proceso de formación de identidad, Laclau (2005) busca conocer el papel que juegan las ideas al momento de evocar al pueblo en un contexto cultural y político determinado para modificar los contenidos intelectuales o sentidos en la ciudadanía. Worsley, citado por Laclau (2005), afirma que se construyen "ideas diferentes" en los sujetos a partir del discurso por sus estructuras cognitivas y disposiciones afectivas, así el pueblo no "absorberá" esas ideas directamente (p. 28). No es cuestión solo de la psicología del individuo: esta investigación considera también los contextos sociales y culturales que son parte de las mediaciones del sujeto, con las que forja su identidad política que puede ser articulada, negociada o contraria (en este caso) al proceso político y discurso de Correa.

Si todo lo mencionado es un proceso hegemónico, además existe posibilidad de que puedan desapegarse elementos de la cadena equivalencial y convertirse en "significantes flotantes", indica Laclau (2005). El proyecto se renovará constantemente por las negociaciones permanentes, incluso la acción discursiva del líder está propensa a ser fracturada por los ciudadanos mediante sus significaciones y agenciamientos al ya no sentirse identificados. Este es un punto que interesa en el presente artículo: cómo se ha modificado o mantenido la relación de los sujetos de estudio con el discurso de Correa para conformar esa cadena equivalencial tras diez años de gobierno, sus motivaciones y lecturas sobre el proceso.

\section{Rafael Correa y su discurso}

A Correa lo llamaron "líder personalista", con discurso esperanzador o articulador (Roberts, 2008, p. 58). Apareció en la política como ministro de Economía en 2005, luego fue candidato con Alianza PAIS en 2006 y empezó su labor en la presidencia de Ecuador en 2007. Impulsó la desconfianza en el modelo representativo tradicional al vincular a las agrupaciones políticas vigentes en la "partidocracia", de forma despectiva, por lo que al contrario denominaba a su proyecto la Revolución Ciudadana, con un llamado discursivo a la participación ciudadana. En la Asamblea Constituyente que convocó en 2008, su movimiento obtuvo mayoría y estuvo en contacto con grupos políticos progresistas; se formó una coalición plural de sectores sociales y estratos medios. El discurso presidencial de Rafael Correa implementó una lucha estratégica en la permanente disputa del sentido con la ciudadanía. Este 
discurso evocaba al pueblo contra las oligarquías por su responsabilidad en la debilidad institucional que sufría el país:

Correa fue construido en la encarnación de los ideales de la Revolución Ciudadana que devolvería la soberanía, la dignidad y el poder a los ciudadanos. Fue un nuevo paladín de la gesta redentora de la patria, el mesías que lideraría a la ciudadanía a un futuro donde la justicia social reemplace las desigualdades de la larga noche neoliberal (De la Torre, 2015, p.149).

Ubicaremos lo que Verón (1987) denomina "prodestinatarios" (partidarios, quienes comparten sus mismos objetivos políticos) para interpelar al pueblo se instauró el eslogan de "Revolución Ciudadana". En los mítines de Correa se incluyó a grupos que estaban desilusionados de la política (De la Torre, 2012, p. 152), por ejemplo: obreros, comerciantes, afiliados, campesinos, pescadores, artesanos, indígenas, montubios, "cholos", transportistas, jubilados, adultos mayores, profesores, jóvenes, "latin kings" y "ñetas" (antiguas pandillas urbanas), empleadas domésticas, trabajadoras sexuales, recicladoras, entre otros (Correa Delgado, 2015). El líder buscó un lazo directo con estas personas para reconocerlas e incorporarlas mediante la enumeración (Laclau y Mouffe, 1987) a un discurso político con una pluralidad de participantes subalternos (De la Torre, 2012, p. 152).

Siguiendo a Verón, si ubicamos ahora a los "contradestinatarios" tendremos a quienes son excluidos del "nosotros". Correa habló sobre la "larga noche neoliberal" (con una retórica antioligárquica) concebida como el pasado: fue representada como "payasos" y "dinosaurios" que se extinguían, lo que deslegitimaba a esos actores (De la Torre, 2015). Acusó a los políticos de derecha por ser representantes de esas élites económicas. La prensa privada también fue criticada por estar aliada a los intereses de los grupos de poder.

Otro elemento de su discurso es la "refundación del país", dejar atrás la estructura que estaba vigente para reemplazarla por un nuevo orden a favor del pueblo: "Ecuador ya cambió, ;este es el Ecuador de los sueños cumplidos, de la justicia histórica y de la dignidad" (Correa Delgado, 2015). La noción del nacionalismo estuvo en su discurso con el regreso del ideal de la "patria" como metacolectivo que trataba de aglutinar, de forma moral, al "nosotros" en el proyecto político, como en "la patria ya es de todos" o "la patria ya cambió". También se representó a los "otros" en relación a este mensaje: se 
utilizaban las frases "enemigos de la patria" o "antipatriotas" para atacar a los opositores. Asimismo, el líder se mostró como la reencarnación del pueblo: "Sé bien que yo ya no soy yo, soy todo un pueblo" (Correa Delgado, 2015).

\section{Los estudios de recepción, televidencias y lecturas}

Para analizar la relación entre los discursos políticos de Rafael Correa y los ciudadanos en un contexto definido, acudiremos a los estudios de recepción, cuyo objetivo sería "dar cuenta de las posibles combinaciones y/o 'negociaciones' entre diferentes elementos en los intercambios mediáticos para comprender la producción misma de sentido, las fortalezas interpretativas y las significaciones que de todo ello resulten" (Orozco, 2006, p. 23). Se trataría de una forma de explorar el poder: sus fisuras y fracturas históricas mediante la indagación de los sentidos de los sujetos, para verlos no solo como reproductores, sino como creadores de significaciones. En este caso, sobre el discurso del político y la construcción del pueblo.

Asimismo, exploraremos cómo los sujetos se reapropian de los contenidos discursivos, puesto que son agentes de producción de significado (Martin-Barbero, 1987). El aporte de este autor es el concepto de "mediaciones" para analizar el proceso de comunicación sin dualismos de dominantes/dominados. Para llevarlo al análisis empírico, Orozco (2001) propuso la teoría de la "mediación múltiple", que se refiere a la negociación que hacen los televidentes (su teoría se basa en la recepción de televisión) con los mensajes. En este sentido, el mencionado autor, citado por Lozano (1996), sitúa a las "televidencias" como un proceso mediado de interacción de las personas con lo audiovisual (p. 209).

Para este trabajo sobre recepción de discursos políticos, acudiremos también a los conceptos de Hall (2004) sobre las lecturas preferentes o dominantes que aparecen cuando se "decodifica" el mensaje en los mismos códigos que fueron "codificados". También el significado negociado (que está atravesado por contradicciones) posee elementos de confrontación que toman en cuenta las definiciones hegemónicas y opera con sus propias normas. Y la lectura oposicional proviene de las significaciones de negación de los códigos, mediante los que fueron codificados los mensajes, produciendo una recepción contraria a la intención del productor (Hall, 2004, p. 235). Esto servirá para 
conocer si en las televidencias de los puesteros existen lecturas a favor, negociadas o en contra del discurso de Rafael Correa.

\section{Metodología}

El estudio se desarrolló en la feria libre de La Ofelia, en Quito, lugar de encuentro multiétnico de comerciantes populares. Al ser un estudio de recepción, se considera a los sujetos como "activos" dentro en un proceso complejo y hegemónico. De estos se buscará captar las mediaciones sociales y su producción social de sentido (experiencias, vivencias y juicios sobre lo político) a través de sus lecturas sobre el discurso presidencial.

Para ello acudimos a un enfoque cualitativo y como técnica principal se realizaron entrevistas abiertas que "se fundamentan en una guía general de contenido y el entrevistador posee toda la flexibilidad para manejarla" (Hernández, Fernández \& Baptista, 2006, p. 597). De agosto de 2016 a inicios de enero de 2017 (en su espacio cotidiano, la feria de los viernes y sábados de cada semana) se entrevistó a 23 puesteros (17 mujeres y 6 hombres), porcentaje similar a la existencia de mujeres (80\%) y hombres $(20 \%)$ en la feria. El contacto fue personal y por dinámica de "bola de nieve"2.

Las entrevistas fueron breves y en momentos en que no se interrumpía el trabajo de los puesteros (horarios preferentes los viernes entre 11:00 y 14:00, cuando hay menor afluencia de gente) para que puedan responder con tranquilidad. Además, como estrategia se acudió a comerciantes que estaban vendiendo en grupos, ya que así uno de ellos podría dar la entrevista mientras los otros vendían, así como se prefirió entrevistar a grupos de puesteros, pues se conocen entre ellos y se desarrollan con mayor confianza las lecturas sobre los temas indagados.

Sobre los objetivos específicos, se conocieron las mediaciones múltiples (Orozco, 2001) que contribuyen a comprender la recepción en los sujetos. En todas las mediaciones indagadas se utilizaron entrevistas a los puesteros:

2. Desde un contacto inicial, se consiguen otros: un comerciante refiere a personas que le gusten hablar sobre la política o refieren a amigos de la feria. 
- Mediación individual, para conocer sus experiencias y recuerdos en relación con la política y los políticos: "se reconoce un desarrollo cognoscitivo y emocional específico y generador de unas prácticas culturales concretas [...] surge en primer lugar de los esquemas, repertorios o guiones mentales de significados por los cuales cada sujeto particular otorga un sentido a los mensajes" (Vega Montiel, 2004, p. 139).

- Mediación de referencia, también con entrevistas a dirigentes y datos de tesis e investigaciones previas hechas en el sitio: "comprende todos los rasgos identitarios del sujeto que lo sitúan en contextos determinados; por ejemplo, su edad, género, clase social y etnia" (Vega Montiel, 2004).

- La mediación situacional se refiere a los distintos escenarios por los que transcurre el sujeto y en los que se reapropia de los contenidos consumidos de los medios de comunicación acerca de la política. Aquí intervendrían los valores del grupo de audiencia en el proceso de recepción (Vega Montiel, 2004, p. 140).

- La mediación institucional, que tiene relación con la situacional y reconoce a las múltiples instituciones que pertenecen los sujetos al mismo tiempo (familia, la feria, la política, los políticos), sus condicionamientos y reglas.

Figura 1: Esquema de metodología usada en la investigación.

\begin{tabular}{|c|c|c|c|}
\hline \multicolumn{4}{|c|}{ CONSTRUCCIÓN SOCIAL DE SENTIDO } \\
\hline \multirow{5}{*}{$\begin{array}{l}\text { MEDIACIONES } \\
\text { MÚLTIPLES }\end{array}$} & INDIVIDUAL & \multirow{5}{*}{$\begin{array}{l}\text { TELEVIDENCIAS } \\
\text { LECTURAS } \\
\text { (PREFERENTES, } \\
\text { NEGOCIADAS U } \\
\text { OPOSICIONALES) }\end{array}$} & $\begin{array}{l}\text { SIGNIFICANTE } \\
\text { VACÍO }\end{array}$ \\
\hline & REFERENCIA & & ANTAGONISMO \\
\hline & SITUACIONAL & & PUEBLO \\
\hline & \multirow{2}{*}{ INSTITUCIONAL } & & $\begin{array}{c}\text { DEMANDAS } \\
\text { INSATISFECHAS }\end{array}$ \\
\hline & & & $\begin{array}{l}\text { SIGNIFICANTES } \\
\text { FLOTANTES }\end{array}$ \\
\hline \multicolumn{2}{|c|}{ ENTREVISTAS + BIBLIOGRAFÍA } & \multicolumn{2}{|c|}{ VISIONADOS + ENTREVISTAS } \\
\hline
\end{tabular}

Fuente: Elaboración propia. 
Mientras que con el visionado (individual, en parejas o grupos) de un video-resumen de los "Enlaces Ciudadanos" (programa conducido por Rafael Correa y transmitido los sábados por radio y televisión, con duración cercana a las tres horas) se obtuvieron las televidencias de primer y segundo orden (Orozco, 2014), pues se producían conversaciones y debates que mostraban la apropiación de los discursos. Tras el visionado, se realizaron entrevistas con las que se identificaron las lecturas preferentes, negociadas u oposicionales acerca las categorías que utiliza Laclau (2005) sobre la construcción del pueblo: a) significante vacío, el líder y sus formas de comunicación (Rafael Correa y los "Enlaces Ciudadanos"); b) antagonismo hacia los "otros" (el pasado, las élites y los medios de comunicación); c) el pueblo; d) las demandas insatisfechas; y e) los significantes flotantes (rupturas en cadena equivalencial). Los resultados serán expuestos en los siguientes puntos.

\section{Los sujetos de estudio y mediaciones: comerciantes de la feria de La Ofelia}

El funcionamiento de la feria libre empezó en 1989. Tiene como propósito regular los precios de productos, evitar la especulación mediante la venta directa por parte de los productores (Guerrero, 2012). Es un lugar de disputas ante las decisiones gubernamentales y administraciones municipales, pues mediante decretos se ponía en duda su permiso de funcionamiento y también en los cabildos sonaba siempre la idea del desalojo, ya que el terreno en el que están instalados es ajeno: pertenece al Instituto Ecuatoriano de Seguridad Social. Los trabajadores (como unión para defender sus demandas) formaron en 1996 la Asociación de Feriantes (mediación institucional) y en 2016 ya tenía 1647 ciudadanos registrados. Por ese motivo, la política y los políticos han estado cerca a esta feria, con ofertas o amenazas de desalojo de los puesteros.

En cuanto a las mediaciones referenciales, la feria es un lugar de acogida de estas personas que provienen de provincias como Pichincha, Carchi, Cotopaxi, Imbabura, Chimborazo, Esmeraldas, Santo Domingo y Tungurahua. Hay presencia multiétnica: ciudadanos afroecuatorianos, indígenas y mestizos. También en sus hijos y nietos se muestra la hibridación con lo urbano, ya que nacieron en la capital del país, a la vez que comparten con sus familias otras tradiciones y los acompañan en visitas a sus sitios de origen. Los tenderos del sitio tienen entre 18 y 65 años. 
Esta población es de estrato económico medio y bajo; tiene como principal actividad el comercio. En la feria hay un 80\% de mujeres (Miriam Suquitana, comunicación personal, 11/XI/2016). En esa labor, ellas obtienen recursos para su independencia económica. Todos estos rasgos presentados atraviesan su lugar de enunciación y se verán reflejados en las lecturas recogidas.

\section{Espacios de mediación situacional de los sujetos de estudio}

La feria libre es un lugar de mediación situacional e institucional que evidencia una cultura política de la acción popular (Martín-Barbero, 1987, p. 103). No es solo resistencia pura o alienación de los comerciantes, sino es esa forma de "subalternidad" presente que puede generar tensión al interpretar los acontecimientos y reapropiárselos en su contexto social y tiempo histórico. En la feria, mediante la comunicación cara a cara entre comerciantes vecinos y coterráneos, se producen interacciones según la coyuntura de lo que ocurre en la política con sus negociaciones de sentido ante esporádicas visitas preelectorales.

Vino el Lucio [Gutiérrez], le dijimos que es mentira, que si ellos ofrecen y no saben cumplir, mejor no ofrezcan. Que solo cuando quieren entrar al trono nos dan la mano y cuando están en el trono se olvidan de nosotros (María Urquizo, comunicación personal, 22/X/2016).

Todos han venido cuando se elige alcalde o presidente: Correa, Noboa, el Rodas. Sabíamos pelear entre las dos, yo era en contra del Correa y ella era a favor del Correa, ahora ya está igual que yo, solita se convenció (Fabiola Gualoto, comunicación personal, 22/X/2016).

El "trono" es el lugar de privilegio de la política, de diferenciación y superioridad ante el pueblo. Otros lugares para la mediación, en este caso institucional y situacional (Orozco, 2014), para construir sentidos son los hogares. En las reuniones familiares y en los diálogos de pareja se conversa sobre la situación del país, información que luego circula en otros espacios: "se habla más de política en mi casa, luego en el mercado también cuando se va por ahí se dice mira está mejor el Lasso o el Correa" (Ligia Sabando, comunicación personal, 22/X/2016). Las televidencias de segundo nivel se ubican entonces en el mercado y el hogar. 
Además, se produce la intervención de los medios para organizar el tiempo y las rutinas, no para obstaculizarlas, sino para armonizarlas y estructurarse conjuntamente. Esto ocurre con una atención intermitente en las televidencias de primer orden mientras realizan más actividades para que las comerciantes tengan acceso a lo público (Morley, 1996, p. 383), a las noticias de la política: "Viendo televisión, es más que la radio, mientras se hace alguna cosa o cocinando, ahí escuchamos" (Fabiola Gualoto, comunicación personal, 22/X/2016).

El uso de los medios de comunicación es múltiple: para obtener información política, con otros fines personales según sus creencias y gratificaciones, aquí ganan terreno los medios locales o especializados, por ejemplo, en el tema religioso. "Me informo de la política en las noticias, a veces en Internet o en radio. A mi esposo le gusta escuchar, él me informa. Como soy cristiana lo que más veo es la HCJB, el canal 27 Asomavisión" (María Urquizo, comunicación personal, 22/X/2016).

\section{Lecturas sobre el discurso presidencial}

\subsection{La política y la experiencia de los comerciantes}

La política incluye reflexión desde la experiencia y lo cotidiano. Los sujetos resaltaron su condición de comerciantes independientes, decidieron no apoyar como colectivo a ningún candidato por los ofrecimientos incumplidos y demandas insatisfechas. Este es el punto identificado para su significación como una "comunidad interpretativa". Orozco, citado por Varela (1999), da su concepto: "un conjunto de sujetos sociales unidos por un ámbito de significación del cual emerge una significación especial para su actuación social (agency)" (p. 143). Los puesteros rechazan ser vistos como masa utilitaria para beneficios de partidos políticos: "Solo es hasta dar el voto nada más. Nos ofrecieron que van a arreglar la feria. [...] hay mucha corrupción" (María Urquizo, comunicación personal, 22/X/2016).

El sentido común articulado en los comerciantes enuncia como principio general que la política es corrupta, deslegitiman al sistema político por haber tenido un fracaso moral de quienes toman el poder. Esto lo enlazan y ponen en comparación con sus condiciones objetivas de vida: "Buscan be- 
neficio para ellos, si supieran el trabajo que nosotros hacemos dijeran 'esto tiene que parar y hasta aquí' [...] como nunca nacieron por esta situación, ni nunca pasarán va a ser muy difícil" (Sandra, comunicación personal, $22 / \mathrm{X} / 2016$ ). Ella relaciona su vivir, pues se traslada a diario de norte a sur en un viaje de dos horas para cargar y descargar las papas que vende, su familia indígena de Chimborazo migró a la Amazonía y a Pichincha para obtener un sustento de vida.

María Hortensia es del Valle del Chota (población afroecuatoriana), tiene 55 años, toma como verdad universal que el gobierno siempre ha sido solo para "los ricos" y no para "los pobres". La mediación individual y de referencia reflejan la articulación del racismo y clase. Sergio es afroecuatoriano, su sentido sobre la política tenía relación al trato discriminatorio que recibían él y sus familiares desde el Estado, con la burocracia y para conseguir un empleo: "Antes lo que más jodía a uno era el racismo, de los políticos mismos. Iba al registro civil o a una institución pública, no me atendían, se hacían los que no me ven. Buscaba un empleo y me decían 'no, ya no hay', porque uno era negro" (Sergio Maldonado, comunicación personal, 31/XII/2016).

Otro factor ha sido la relación entre el Estado y el sector privado. Por ejemplo, la estructura conformada en la última década del siglo XX permitió el "salvataje bancario" que afectó a la población y la despolitizó: "Me creó desconfianza la política cuando estuvo Jamil Mahuad, cuando hubo banqueros, el feriado bancario. Ahí dolarizó y el sucre ya no valía nada. Yo era recién casado" (Juan Morocho, comunicación personal, 6/I/ 2017). Este caso es reiterativo en las entrevistas.

\subsection{EI líder, Rafael Correa}

Los frecuentes recorridos de Rafael Correa por el país sirvieron para que su palabra sea recibida en forma del "cara a cara" para gestionar las necesidades y demandas insatisfechas localizadas. Correa los visitó una ocasión en La Ofelia. El ethos efectivo (Maingueneau, 2002) en los comerciantes sobre él era de ser cercano a la gente, lejos de esa imagen sacralizada de autoridad, además se resalta la ilusión política por el carácter mesiánico para grupos subalternos: 
Una persona que vino a cambiar el país, se le vio como el salvador de los pobres (De los Ángeles Rea, comunicación personal, 6/I/ 2017).

Político nuevo, un tipo salvador, teníamos aspiraciones [...] él nos da la mano, saluda, habla nuestro idioma (quichua). Lo que ofrecía cumplía: dar beneficios a los pobres (Juan Morocho, comunicación personal, 6/I/ 2017).

Por otro lado, sus apariciones mediatizadas o en el "cara a cara" generaron que sea más visto y más "significado" por la ciudadanía. Ese ethos también posee lecturas oposicionales, totalmente contrapuestas a la mostrada antes; por ejemplo, de un activista político y comerciante de pollos, él afirma que Correa se aprovechó del contexto de movilización social existente para luego polarizar a los ciudadanos de forma moral ("correísmo") como enemigos y no contra las élites: "Correa es un político populista que aprovechó la rebelión del 20 de abril de 2005 para ingresar al poder. Es un tipo autoritario, que se cree dueño de la verdad, que tiene el ego muy encendido [...] ha dividido al país en correístas y no correístas" (Aníbal Moreno, comunicación personal, 31/XII/2016).

\subsection{Sobre los "Enlaces Ciudadanos"}

Hasta el 13 de mayo de 2017, se transmitieron 522 de estos programas sabatinos (de 10:00 a 13:30) desde distintos sitios del país e incluso desde ciudades del extranjero con alta presencia de migrantes compatriotas. En este, el presidente explicaba (con un rol de profesor) los temas de manejo gubernamental en lo económico y político.

Dicho programa era visto solo por algunos comerciantes de La Ofelia, porque coincidía con su horario de ventas. Otros lo observaban las repeticiones de los domingos, además de ver fragmentos del discurso de Correa que se recogían en los noticiarios. Se configuró como mediación para una parte de los entrevistados, ya que significaba una rendición de cuentas hacia los representados por parte del representante de forma directa: "Con el Enlace se sabe qué se está haciendo, en qué se ha invertido el dinero" (Sergio Maldonado, comunicación personal, 31/XII/ 2016).

Además, en el "Enlace...", el código del idioma quichua aumentó la relación mediática con sus hablantes, mediante un segmento con un traductor: 
"Hay muchas personas del campo que no entienden el castellano y ya ven en quichua y entienden, ya pueden saber todo lo que hace en la semana, lo que ha sucedido" (Juan Morocho, comunicación personal, 6/I/2017). El código lingüístico y de contenido utilizado por Correa causaría interrupciones o distorsiones del mensaje, teniendo distintos resultados en el proceso de comunicación: "Hay partes que no se entienden porque son técnicas; un ingeniero sí, pero la gente del campo o del mercado que no sea estudiado no va a entender" (Juan Morocho, comunicación personal, 6/I/2017).

Las estructuras significativas de los ciudadanos también actúan en cuanto al contenido político, pues este formato del programa permitiría visibilizar otros rasgos del ethos del mandatario al construir al "otro" de forma denigrante: "Es como si él se burlara de otras personas, hiciera chiste, pero él como presidente debe ser correcto en las cosas" (Juan Morocho, comunicación personal, 6/I/2017). E incluso hay críticas por intentos de manipulación mediante el uso de la espectacularización de la política: "Es una confrontación, es un lugar donde él derrama su odio [...] un discurso como circo, como en el imperio romano, un espectáculo para tenerle al pueblo ahí entretenido y que no reaccione" (Aníbal Moreno, comunicación personal, 31/XII/2016).

Más allá de la capacidad de determinación del mensaje en la producción del discurso presidencial, otras mediaciones entran en juego. Los comerciantes relacionan la infraestructura implementada como parte de su experiencia: "Hay que darse cuenta por su propia cuenta, no por lo que diga el presidente. No solamente se ve en la tele, en los 'Enlaces', se ve en los hechos, vaya a Ibarra, San Lorenzo, todas las vías se encuentran en perfecto estado" (Sergio Maldonado, comunicación personal, 31/XII/2016).

\section{4. ¿Los otros? El pasado, las élites y los medios privados}

\subsection{1. ¿El pasado no volverá?}

Correa empleaba una serie de frases recurrentes, entre las que destacaban: "el pasado no volverá", "la partidocracia" y "los mismos de siempre". Criterios oposicionales reiterados se presentaron en este caso, ya que se mantienen significaciones positivas acerca de la labor de actores políticos del denominado "pasado", que eran de derecha: "Pero por quien votara es por el Lucio, él sí 
hizo buenas obras. Puro impuestos nomás ha puesto el Correa. Esto puede cambiar si es que gana la Cynthia, a los pobres iba a ayudar con lo de la luz. Una mujer va a hacer cambiar al país" (Elena Viteri, comunicación personal, 23/XII/2016).

Una lectura negociada fustiga al pasado, pero también al gobierno de Alianza PAIS por incoherencia ideológica en su crítica a la partidocracia: "Ha enfrentado a grupos de poderes, de la burguesía costeña y serrana, pero es un doble discurso, porque a la vez está pregobernando con los mismos de siempre, los socialcristianos están en el gobierno, la Izquierda Democrática, es parte del juego político" (Aníbal Moreno, comunicación personal, 31/XII/2016). El comerciante se apropia de la frase "los mismos de siempre" que usaba frecuentemente Correa, en este caso para refutar al mismo Correa.

\subsubsection{Las élites}

Retomamos lo indicado en un apartado anterior sobre la relación "Estado-sociedad". Al compararla con el discurso de Correa, los comerciantes comparten la lectura preferente para construir como un "otro" a los grupos de poder, pues en la política dominaron las élites:

Ellos trabajan por su lado, como tienen su empresa, su banco abren otro banco, ganan su plata y no les importa lo que pase al pueblo (María, comunicación personal, 30/XII/2016).

Recién este Gobierno les puso un alto, los otros no. Y pienso que si viene otro presidente no lo hará, porque ellos se dejan manejar por el dinero y por el bienestar propio (Sandra, comunicación personal, 22/X/2016).

El sector financiero fue el más aludido en las lecturas sobre el pasado, ya que se fijaron sentidos sobre esos grupos de poder por las grandes afectaciones sufridas. Un joven impugna la división social del trabajo y las desigualdades de salario entre directivos y trabajadores: "Un gerente del banco gana por miles de miles y vuelta en comparación de un cobrador gana 1.500 dólares que pasa en la ventanilla. Vuelta la comparación en una empresa la gente que con horas extras gana 500 o 700 máximo así. No es equitativo (Álex Minda, comunicación personal, 23/XII/2016). En otros casos está presente la naturalización de esas diferencias, entre propietarios de medios de producción y 
trabajadores: "Es algo que siempre tiene que haber, la oligarquía, porque si no hubiera oligarquía dónde trabajáramos" (Fabiola Gualoto, comunicación personal, 22/X/2016).

\subsubsection{Los medios de comunicación}

La tensión por la disputa de la verdad entre los medios de comunicación privados y el gobierno también es captada por la ciudadanía: "Los medios de comunicación no dicen la verdad. Me doy cuenta por mi pueblo, no hay ayuda. En eso debería enfocarse [...] en las necesidades" (María Hortensia, comunicación personal, 23/XII/2016). Consideran a los medios como aliados al poder para manipular, pero al mismo tiempo critican que el Presidente haya judicializado a algunos medios o periodistas por su tarea:

Los medios siempre han manipulado a la gente, siempre han estado detrás de los gobiernos, también es un grupo poderoso. Pero a la vez es criticable porque Correa se vale de eso para atropellar libertades, derechos, figúrate los juicios a Carlos Calderón, a Diario El Universo, a Los 4 pelagatos, Jeaneth Hinostroza han sido perseguidos (Aníbal Moreno, comunicación personal, 31/XII/2016).

También la desconfianza por los medios se debe a su reclamo a la representación negativa de su feria libre, ya que los medios serían parte de quienes impulsaron indirectamente los pedidos de su desalojo: "Muestran quejas de moradores del barrio, sacan de la basura, mala imagen y luego quieren mandar botando (las autoridades) al mercado" (Juan Morocho, comunicación personal, 6/I/2017).

\subsection{Cumplimiento de demandas insatisfechas}

Ante el incumplimiento de las demandas sociales, los comerciantes exaltan al régimen de Correa por la fuerte inversión en obra social para los grupos más vulnerables, lo cual antes estaba ausente como política de Estado: "Hizo que las amas de casa fueran afiliadas al seguro. Obviamente también las carreteras, las escuelas. Mi familia vive en una zona rural de Esmeraldas, selva adentro más o menos, entonces el gobierno mandó a que les hagan baños, agua potable" (Martha Arroyo, comunicación personal, 23/XII/2016). 
Los puesteros destacan la mejoría en infraestructura estatal, calidad de servicios públicos para el ciudadano común y de estructuras de funcionamiento de la burocracia en algunas instituciones: "Se da cuenta cómo es la atención en el Registro Civil, esa corrupción que había antes, tenía que pagar para sacar una cédula, ahora eso ha cambiado, en cinco minutos está con su cédula. La escuela mejoró, capacitó profesores, médicos" (Sergio Maldonado, comunicación personal, 31/XII/2016). El mismo entrevistado indicó que "ahora un pobre puede ir a escuela de ricos", reflejando una movilidad social en el mejoramiento de sus condiciones.

Al ser ciudadanos de estratos bajos y medios, la ayuda estatal cobra importancia para sus vidas porque les ayuda a enfrentar las problemáticas estructurales: "Un Presidente ejemplar, yo decía: esta presidencia no se compara a ninguna de las que hubo [...] No me quejo, soy operada, nos dio la salud que es mejor, el estudio que quitó que cobren las matrículas, es hermoso" (De los Ángeles Rea, comunicación personal, 6/I/2017). Los bonos y subsidios son medidas de redistribución de ingresos, los puesteros las asimilan como una preocupación del gobierno por los más desposeídos: "La gente que coge el bono muchas veces no tiene ni para un pan. Mis papás son de la tercera edad, ya no trabajan, reciben el bono cada mes, con eso ellos que dicen: con eso estoy ahorrando para las medicinas" (Ligia Sabando, comunicación personal, 22/X/2016).

A pesar del declive económico y político del gobierno (desgaste del propio Correa, el terremoto de 2016, la caída del precio del petróleo y valorización del dólar) se mantuvo este sentido de cumplimiento de varias demandas que estaban insatisfechas.

\subsection{Ruptura de la cadena equivalencial}

El proceso político varió en su composición de los grupos que lo respaldaban y esto se reflejó entre los comerciantes. Hubo una renovación de la cadena equivalencial del denominado "pueblo", según la teoría de Laclau (2005). Aparecen los "significantes flotantes", ya no se sentían representados por el líder (el "significante vacío") ni por el proyecto: "es una dictadura civil disfrazada de democracia donde se toma todos los poderes, donde se creen los emperadores" (Aníbal Moreno, comunicación personal, 31/XII/2016). 
Una mediación importante en su vida es lo económico, por sus necesidades como grupos subalternos. Uno de los principales reclamos, "hay cosas que sí se le ha pasado la mano" (Sergio Maldonado, comunicación personal, 31/ $\mathrm{XII} / 2016$ ), fue sobre las responsabilidades con el Estado recaudador, un mayor pago de impuestos. Reconocen al Estado como eje central para impulsar obras, política pública y dinamizar la economía, pero su estancamiento causó tensión al ya no existir bonanza en el país, lo cual repercutió en sus ventas y a la vez ellos seguían pagando tributos:

Vendíamos unos 200 o 300 melones, ahora vendemos 100 melones en dos días, ya no llega la gente como antes (Paulina Untuña, comunicación personal, 30/XII/2016).

Estamos con una deuda grande, que solo se invierte en carreteras [...] Bueno también sí sirven las carreteras, pero ¿podemos comer de las carreteras, vivir de ellas? (María, comunicación personal, 30/XII/2016).

El reclamo hacia el proyecto de inversión estatal da cuenta que restaban demandas insatisfechas, en este sentido sobre productividad. Otra demanda tuvo relación con la situación de movilidad social al no haber ampliado el acceso (cupos) a estudios universitarios o superiores, ya que muchos jóvenes de grupos subalternos se graduaron de la secundaria al ser la educación gratuita: "Una universidad privada de 2.300, 3.000 dólares no se puede ingresar porque ese costo es para "pelucones' ${ }^{3}$ y habiendo universidades fiscales a las que ellos puedan ingresar y seguir adelante con sus estudios sería un éxito para el país" (Sergio Maldonado, comunicación personal, 31/XII/2016). A esto aún se sumaban los pedidos por mejoras en condiciones básicas como vivienda y trabajo.

En cuanto a la lectura oposicional, un puestero afirmó que las políticas del régimen no han sido radicales para disminuir esas desigualdades económicas del pueblo con relación a los grupos de poder: "los ricos han estado con Rafael Correa, vea la banca 3 mil millones de utilidades" (Aníbal Moreno, comunicación personal, 31/XII/2016). Esto, a pesar de que la banca fue criticada en lo discursivo por Correa.

3. El discurso de Correa se apropia del calificativo "pelucones" como sustantivo y adjetivo referente a la gente con amplio capital económico, para criticar al mismo accionar del régimen en ese sentido. 


\section{7. ¿Quiénes construyen el pueblo?}

La construcción de la cadena equivalencial se vio debilitada: los entrevistados no nombraron un colectivo de identificación (Verón, 1987) como el de "Revolución Ciudadana". Sin embargo, sí se identificaron como parte de un "pueblo", que sería un meta colectivo que los abarca y que funda su identidad como grupos subalternos para tener capacidad de elección de sus representantes en las formas institucionales y legales existentes: "Es la gente, tiene todo el poder porque decide si el Presidente puede seguir o puede irse. Si nosotros decimos Presidente queremos que salga, con recoger firmas, el presidente queda nulo" (María Maldonado, comunicación personal, 23/XII/2016).

Esta visión es críticamente ampliada por un comerciante. Rechaza que el ejercicio de la democracia se restrinja solo a los sufragios y cree que el pueblo debe ser el gestor permanente de los cambios radicales, sin la lógica vertical del sistema político que lo impide.

El pueblo es la primera autoridad, el soberano, el mandante de los politiqueros, de los gobernantes, pero lamentablemente aquí en Ecuador el pueblo tiene la culpa, solamente a veces va deposita su voto y allá. Luego cuando viene el paquetazo ahí sí a chillar porque no hay verdaderamente ese ejercicio del poder del pueblo. El pueblo tiene que ser el gestor de cambios radicales, no solamente viene un gobierno y ya, los Mesías [...] El pueblo tiene que estar en el cambio de educación, salud (Aníbal Moreno, comunicación personal, 31/XII/2016).

Otras vivanderas resaltan la capacidad crítica y reflexiva del pueblo ante las élites y gobernantes, se "desidentifican" con Correa, creen que el pueblo se construye fuera de un gobierno: "Acerca del pueblo y el Presidente Correa, al pueblo le amenaza que le va a mandar preso [...] En el pueblo está la fuerza. Si es que no le agrada el presidente puede coger y botarle" (Elena Viteri, comunicación personal, 23/XII/2016). De los Ángeles Rea tiene 48 años, ha trabajado desde los 11. Ella recuerda cómo el pueblo se articulaba y luchaba en las "bullas" (como expresión política y de movilización) por sus condiciones sociales:

Cuando hacían bulla los universitarios era porque algo subía de precio [...] nos apoyaban con su fuerza, nos cuidaban a nosotros los pobres. Desde que entró el señor Correa no hay nada de eso. Por medio de los universitarios en- 
traban trabajadores, indígenas, todo el pueblo se paraba y luchábamos. Todo político se quedaba "stop" ahí, porque se paraba el pueblo (De los Ángeles Rea, comunicación personal, 6/I/2017).

Por otro lado, se afirma que el pueblo tiene limitaciones por la estructura política: el pueblo aceptaría la subordinación ante la autoridad, porque si no habría represalias contra la gente: “¿Qué poder tiene el pueblo? Le cuento que no tiene mucho verá, así como eligen, quieren derrocar, mandarle del mando, pero no pueden porque ya es presidente y ya acatan lo que digan él, sino están mal vistos (Paulina Untuña, comunicación personal, 30/XII/2016).

\section{A modo de cierre}

En la metodología se procuró una adaptación de las teorías para construir un enlace entre mediaciones múltiples, televidencias y el tipo de lecturas, con relación a la teoría de construcción del pueblo. Esto nos permite conocer el proceso de comunicación y significación de los puesteros desde sus condicionamientos (dada su situación de subalternidad), los espacios por los que circulan esas ideas (hogares y el mercado) y su puesta en escena mediante sus lecturas, las cuales muestran su apego, rechazo o negociación con el discurso político.

La feria popular de La Ofelia es un lugar rico para elaborar un estudio social, ya que están presentes varias culturas, marcadas por los distintos orígenes, etnias y trayectorias de los comerciantes. Es un lugar de mediación, una comunidad interpretativa para tener una postura unitaria de no apoyar (como agrupación) a ningún político. Además, es punto de relación de sentidos para dar como resultado lecturas acerca de la política y el discurso presidencial. A esto se suman sus necesidades específicas, en su situación como migrantes y en la vida diaria como grupo subalterno, que son mediaciones que ponen en negociación sus significaciones.

Hasta el año 2017, la televisión se mostraba como hegemónica entre los puesteros en cuanto a consumo mediático para obtener información sobre temas políticos. Esta práctica se desarrolló más en sus hogares e intervino en la configuración del tiempo de los puesteros, siendo las televidencias de primer y segundo orden las que dominan en ese espacio. Mientras que, en el merca- 
do, las televidencias de segundo y tercer orden sobre el discurso político de Correa son las que más se presentaron, ya que se ponen en discusión estos temas entre vecinos y conocidos de la feria, con lo que la comunicación "cara a cara" permite la reapropiación de esos contenidos.

Las lecturas de los comerciantes en ese periodo final del decenio de Correa mostraron una variación de sentidos con relación al proyecto de la "Revolución Ciudadana", tras su hegemónica presencia. Las identificaciones positivas y las lecturas preferenciales, con relación al proceso de construcción del pueblo, se refirieron más a los primeros años de la gestión, ya que sintieron que las demandas en un inicio fueron satisfechas para grupos subalternos, pero fueron apareciendo nuevas que no fueron cumplidas por las dificultades de la situación económica del país, aparte de los conflictos presentados con el gobierno. Estos fueron factores de mediación para las significaciones de los puesteros sobre Rafael Correa.

Las televidencias sobre el discurso presidencial del mencionado político, en especial a través de su "Enlace Ciudadano", obtuvo lecturas preferentes y oposicionales en medio de un marco de declive de la fase hegemónica. Aunque se resaltaba la presencia del mandatario para informar sobre su accionar, había un rechazo de puesteros a su actitud antagónica mantenida por años.

En cuanto a las lecturas de los puesteros, se refleja el antagonismo contra las élites económicas, empresariales o bancarias del país, como agentes de las desigualdades estructurales, pero es distinta la concepción sobre los gobiernos anteriores (criticados por su inestabilidad) y políticos del denominado "pasado", ya que también hay lecturas de respaldo a esos políticos.

Los comerciantes resaltan la importancia de conformación del "pueblo" (no necesariamente con la "Revolución Ciudadana") para luchar contra un poder hegemónico. Consideran que el pueblo es actor social asociativo, activo y reflexivo, aunque con debilidades por la desmovilización causada incluso por el mismo Correa.

En este sentido, la teoría de Laclau (2005) nos dio herramientas para pensar las articulaciones del proyecto político, pero se requirió una reflexión sobre sus cambios y debilidades en lo político, con su variación a la hora de gobernar, pues a pesar de que en un inicio el proyecto evocó al pueblo, luego tuvo 
una desarticulación progresiva del mismo por el accionar del régimen y de su líder, por las medidas desplegadas como gobierno, así como por los estancamientos en el cumplimiento de demandas sociales y el desgaste por el juego político.

En suma, los sentidos de los comerciantes han estado en medio de esa relación con el sentido común, con las estructuras hegemónicas, con el discurso presidencial y las televidencias, con sus experiencias que han puesto en disputa sus significados, teniendo que ejercer tácticas de creatividad y apropiación desde su lugar de enunciación.

\section{Fuentes consultadas}

Andino Veloz, B. (2017). Sentidos producidos entre los comerciantes del mercado La Ofelia, en Quito, sobre el discurso populista del presidente Rafael Correa (tesis de maestría). Universidad Andina Simón Bolívar. Quito, Ecuador. Recuperado de http://repositorio.uasb.edu. ec/bitstream/10644/5689/1/T2329-MC-Andino-Sentidos.pdf

Cerbino, M., Maluf, M. \& Ramos, I. (2016). Los enlaces ciudadanos del presidente Rafael Correa. Entre la exaltación del pueblo y el combate a los medios. Quito: Flacso.

Correa, R. (1 de mayo de 2015). Discurso en la concentración por el 1 de Mayo. Quito, Ecuador.

De la Torre, C. (2012). Rafael Correa, un populista del siglo XXI. En M. Mantilla, \& S. Mejía (Eds.), Rafael Correa: balance de la revolución ciudadana. Quito: Planeta.

De la Torre, C. (2015). De Velasco a Correa. Insurrecciones, populismos y elecciones en Ecuador 1944-2013. Quito: Corporación Editora Nacional.

Delsol, C. (2016). Populismos. Una defensa de lo indefendible. Bogotá: Planeta. 
Dussel, E. (2006). 20 tesis de política. México, DF: Centro de Cooperación Regional para la Educación de Adultos en América Latina y el Caribe.

Guerrero, M. (2012). Gran reportaje de la feria libre de la Ofelia como muestra de apropiación del espacio urbano (tesis de licenciatura). Universidad Central del Ecuador, Quito.

Hall, S. (2004). Codificación y descodificación en el discurso televisivo. Cuadernos de Información y Comunicación, 9, 215-236. Recuperado de https://revistas.ucm.es/index.php/CIYC/article/view/8162

Hawkins, K. (2008). La organización populista. En C. de la Torre \& E. Peruzzotti (Eds.), El regreso del pueblo. Populismo y nuevas democracias en América Latina (pp. 125-160). Quito: Ministerio de Cultura del Ecuador.

Hernández, R.; Fernández, C. \& Baptista, P. (2006). Metodología de la investigación. México, DF: McGraw Hill Education.

Laclau, E. (2005). La razón populista. Buenos Aires: Fondo de Cultura Económica.

Laclau, E. \& Mouffe, C. (1987). Hegemonía y estrategia socialista. Hacia una radicalización de la democracia. Madrid: Siglo XXI.

Lozano Rendón, J. (1996). Teoría e investigación de la comunicación de masas. México, DF: Alhambra Mexicana.

Maingueneau, D. (2002). Problèmes d'ethos. Pratiques, 113/114, 55-67. Recuperado de https://www.persee.fr/doc/prati_0338-2389_2002_ num_113_1_1945

Martín-Barbero, J. (1987). De los medios a las mediaciones. México, DF: Gustavo Gili.

Morley, D. (1996). Televisión, audiencias y estudios culturales. Buenos Aires: Amorrortu. 
Onofa, L. (2012). Huellas del discurso de Correa en los mercados de Quito. El caso de la Constituyente de 2008. Quito: Corporación Editora Nacional.

Orozco, G. (2001). Audiencias, televisión y educación: una deconstrucción pedagógica de la "televidencia" y sus mediaciones. Revista Iberoamericana de Educación, 27, 155-175. Recuperado de https://www.redalyc.org/pdf/800/80002708.pdf

Orozco, G. (2006). Los estudios de recepción: de un modo de investigar, a una moda, y de ahí a muchos modos. En F. Saintout, \& N. Ferrante (Eds.), ¿Y la recepción? Balance crítico de estudios sobre el público. Buenos Aires: La Crujía.

Orozco, G. (2014). Televidencias. Comunicación, educación y ciudadanía. Guadalajara: Universidad de Guadalajara.

Roberts, K. (2008). El resurgimiento del populismo latinoamericano. En C. de la Torre \& E. Peruzzotti (Eds.), El regreso del pueblo. Populismo y nuevas democracias en América Latina (pp. 125-160). Quito: Ministerio de Cultura del Ecuador.

Sfez, L. (2007). La comunicación. Buenos Aires: Amorrortu.

Varela, M. (1999). Las audiencias en los textos. Comunidades interpretativas, forma y cambio. En A. Grimson \& M. Varela (Eds.), Audiencias, cultura y poder. Estudios sobre televisión (pp. 137-157). Buenos Aires: Eudeba.

Vega Montiel, A. (2004). La decisión de voto de las amas de casa mexicanas y las noticias electorales televisadas. Barcelona: Universidad Autónoma de Barcelona.

Verón, E. (1987). La palabra adversativa. Observaciones sobre la enunciación política. En E. Verón (Ed.), El discurso político. Lenguajes y acontecimientos (pp. 11-26). Buenos Aires: Hachette. 